\title{
TO STUDY THE INCIDENCE OF ANAEMIA AND IDENTIFY AS RISK FACTOR IN CORONARY ARTERY DISEASE
}

\author{
S. Periasamy1 1 V. Umalakshmi², M. Arun ${ }^{3}$ \\ ${ }^{1}$ Reader, Department of General Medicine, Rajah Muthiah Medical College. \\ IInternship (Pharm D), Department of Pharmacy, Rajah Muthiah Medical College. \\ ${ }^{3}$ Internship (Pharm D) Department of Pharmacy, Rajah Muthiah Medical College.
}

\begin{abstract}
AIM AND OBJECTIVE

To identify the incidence of anaemia and to identity anaemia itself as a risk factors in coronary artery disease in rural population.

\section{METHODS AND MATERIALS}

A prospective observational study done in patients admitted with evidence of coronary artery disease in Rajah Muthiah Medical College Hospital from January 2016 to April 2016. Patients with age more than 18 years, both gender, evidence of coronary artery disease were included and secondary case for anaemia were excluded. A detailed clinical history and examination, blood count with smear study was done.
\end{abstract}

\section{RESULT}

In our present study, male predominance (72\%) with more common in age group between (51-60 years) 36\%. Mean haemoglobin level in our study showed $11.70 \mathrm{~g} / \mathrm{dL}$. The incidence of anaemia was $80 \%$ with varying severity 7-9 (2\%), 9-11 (32\%), $11-13(46 \%),>13(20 \%)$ and smear showed microcytic hypochromic dominated with $52 \%$.

\section{CONCLUSION}

Incidence of anaemia observed in rural population with reference to significances of role as risk factor yet to be studied with detailed study. It is important also to investigate secondary cause of anaemia.

\section{KEYWORDS}

Anaemia, Coronary artery disease.

HOW TO CITE THIS ARTICLE: Periasamy S, Umalakshmi V, Arun M. To study the incidence of anaemia and identify as risk factor in coronary artery disease. J. Evolution Med. Dent. Sci. 2016;5(55):3770-3773, DOI: 10.14260/jemds/2016/864

\section{INTRODUCTION}

Anaemia termed as decrease in the oxygen carrying capacity of the blood. Anaemia can occur at any age, but people at the extremes of age more susceptible. Female (Especially in the age group of 15-40) are more prone to anaemia. Anaemia can be broadly categorised into three major classifications according to the size or Mean Corpuscular Volume (MCV) of the erythrocytes (RBCs). (i). Microcytosis (Decreased MCV), (ii). Normocytosis (Normal MCV), (iii). Macrocytosis (Increased MCV).[1] A World Health Organization expert group proposed that "anaemia or deficiency should be considered to exist" when haemoglobin levels is below the levels of $<13 \mathrm{~g} / \mathrm{dL}$ in men and $<12 \mathrm{~g} / \mathrm{dL}$ in women. Symptoms result from impaired from tissue oxygen delivery and may include weakness, fatigue, difficulty concentrating, or poor work productivity. Iron-deficiency anaemia is the most common type of blood disorder worldwide. There is more than 400 type's anaemia, which divided into three groups (1) anaemia caused by blood loss, (2) anaemia caused by decreased or faulty red blood cell production, (3) anaemia caused by destruction of red blood cells. Globally, anaemia affects an

Financial or Other, Competing Interest: None.

Submission 24-05-2016, Peer Review 28-06-2016,

Acceptance 04-07-2016, Published 11-07-2016.

Corresponding Author:

Dr. S. Periasamy,

No. 3, Asirvatham Nagar,

North Main Road,

Chidambaram-608001.

E-mail: drperiasamy53@gmail.com

DOI: $10.14260 /$ jemds $/ 2016 / 864$ estimated 1.62 billion people. This accounts for $24.8 \%$ of the world's population.[2]

Coronary artery disease has been designed as "impairment of heart function due to inadequate blood flow to the heart compared to its needs, caused by obstructive changes in the coronary circulation to the heart". Coronary Artery Disease (CAD) is one of the most common causes of mortality and morbidity in both developed and developing countries. It is a leading cause of death in India and its contribution to mortality is rising: the number of deaths due to coronary artery disease in 1985 is expected to have doubled by 2015.[3] According to reports from the National Commission on Macroeconomics and Health, 62 Million people in India will have coronary artery disease by 2015 with 23 million of these below 40 yrs. of age.[4] The prevalence of classic cardiovascular risk factors such as hypertension, dyslipidaemia, obesity, and diabetes varies widely between different countries and shows some important secular trends. The conventional risk factors for coronary artery disease can be divided into non-modifiable (Age, sex, family history, ethnic background) and modifiable (Smoking, high amounts of certain fats and cholesterol in the blood, physical inactivity, stress, high amounts of sugar in the blood due to insulin resistance, or diabetes) risk factors. ${ }^{[5]}$ As our country is developing soon with over population, it's important to ascertain our own pattern of risk factors for coronary artery disease. Hence, our aim to identify the incidence of anaemia and to identity risk factors in coronary artery disease in rural population. 


\section{METHODS AND MATERIALS}

A prospective observational study done in patients admitted with evidence of coronary artery disease in Rajah Muthiah Medical College Hospital, which is a 1200 bedded multidisciplinary hospital with serving the rural population. A total number of 50 patients were enrolled after getting the informed consent form. Patients with age more than 18 years both gender with evidence of coronary artery disease was diagnosed, established with clinical history, examination findings, ECG-T invasive, Q wave, ST depression, ST elevation, ECHO-presence of regional wall motion abnormally, smoking ( $>20$ cigarettes per day more than 5 yrs.), diabetes, hypertension (Systolic blood pressure $\geq 140 \mathrm{mmHg}$ or diastolic blood pressure $\geq 80 \mathrm{mmHg}$ at repeated measurements or a known history of hypertension), alcoholics, dyslipidaemia, and family history of coronary artery disease] were included in the study. Patients with secondary cause for anaemia (Blood loss, haemorrhoids, malignancy, sickle cell anaemia, aplastic anaemia, psychonomic anaemia, etc. Patients on iron and B12 supplementation) were excluded from the study. A detailed clinical history and examination, blood count (HB, PCV, RBC, TC, PLT, MCV, MCH, and MCHC) with smear study was done. Statistic data are given as mean \pm SD and frequencies for categorical variables. Data were stratified by gender and the presence or absence of anaemia.

\section{RESULTS}

\begin{tabular}{|c|c|c|}
\hline Gender & No. of Patients & \% Patients \\
\hline Male & 31 & $62 \%$ \\
\hline Female & 19 & $38 \%$ \\
\hline \multicolumn{2}{|c|}{ Table 1: Gender-Wise Distribution } \\
\hline
\end{tabular}

The overall gender distribution of the study population revealed that $62 \%$ of patients were male patients and $38 \%$ were female patients.

\begin{tabular}{|c|c|c|c|c|}
\hline Age & Male & Female & No. of Patients & \% \\
\hline $41-50$ & 8 & 2 & 10 & $20 \%$ \\
\hline $51-60$ & 13 & 5 & 18 & $36 \%$ \\
\hline $61-70$ & 6 & 4 & 10 & $20 \%$ \\
\hline$>71$ & 4 & 8 & 12 & $24 \%$ \\
\hline Total & $\mathbf{3 1}$ & $\mathbf{1 9}$ & $\mathbf{5 0}$ & $\mathbf{1 0 0 \%}$ \\
\hline \multicolumn{5}{|c|}{ Table 2: Age-Wise Distribution } \\
\hline
\end{tabular}

In the present study, we observed maximum number of patients were in the earning group (40-60) with domination between the age group of 51-60 years (36\%), which also was supported by male predominance.

\begin{tabular}{|c|c|c|c|c|}
\hline Hb Levels & Male & Female & No. of Patients & $\mathbf{\%}$ \\
\hline $7-9$ & 1 & - & 1 & $2 \%$ \\
\hline $9-11$ & 8 & 8 & 16 & $32 \%$ \\
\hline $11-13$ & 14 & 9 & 23 & $46 \%$ \\
\hline$>13$ & 8 & 2 & 10 & $20 \%$ \\
\hline Total & 31 & 19 & 50 & $100 \%$ \\
\hline \multicolumn{2}{|r|}{ Table 3: Haemoglobin Level Wise Distributions } \\
\hline
\end{tabular}

The present study shows that the maximum number of patients enrolled between Hb levels of 7-13 (80\%). Majority of patients with anaemia between Hb levels 11-13 (42\%), which also was supported by male predominance.

\begin{tabular}{|c|c|c|}
\hline Risk Factor & No. of Patients & \% of Patients \\
\hline Hypertension & 31 & $62 \%$ \\
\hline Diabetes Mellitus & 10 & $20 \%$ \\
\hline Dyslipidaemia & 9 & $18 \%$ \\
\hline HTN+DM & 10 & $20 \%$ \\
\hline DM+DYS & 8 & $16 \%$ \\
\hline DYS+HTN & 9 & $18 \%$ \\
\hline HTN+DM+DYS & 8 & $16 \%$ \\
\hline \multicolumn{2}{|c|}{ Table 4: Other Co-Morbid Conditions } \\
\end{tabular}

Out of 50 patients enrolled in our study, majority of patients having co-morbid conditions of hypertension (62\%) followed by diabetes mellitus (20\%) and dyslipidemia (18\%).

\begin{tabular}{|c|c|c|c|c|}
\hline Types of Anaemia & Male & Female & Total & $\%$ \\
\hline $\begin{array}{c}\text { Microcytic } \\
\text { Hypochromic }\end{array}$ & 16 & 10 & 26 & $52 \%$ \\
\hline $\begin{array}{c}\text { Macrocytic } \\
\text { Hyperchromic }\end{array}$ & 4 & 4 & 8 & $16 \%$ \\
\hline $\begin{array}{c}\text { Normocytic } \\
\text { Normochromic }\end{array}$ & 11 & 5 & 16 & $32 \%$ \\
\hline \multicolumn{4}{|c|}{ Table 5: Smear Distribution of Study Group } \\
\hline
\end{tabular}

This study revealed that majority of patients (52\%) was associated with microcytic hypochromic followed by normocytic normochromic (32\%) and macrocytic hyperchromic $(16 \%)$, which reported nutritional anaemia as the major cause for anaemia in detailed study.

\begin{tabular}{|c|c|}
\hline Red Cell Parameters & Mean \pm SD \\
\hline PCV & $33.5 \pm 4$ \\
\hline MCV & $83.8 \pm 9.3$ \\
\hline MCH & $29.6 \pm 2$ \\
\hline MCHC & $34.5 \pm 2$ \\
\hline Table 6: Statistical Analysis of Red Cell Parameter \\
\hline
\end{tabular}

In our observation, this was the pattern of red cell parameters noted.

\section{DISCUSSION}

This study investigated the prevalence of anaemia in coronary artery disease in rural population. Participants were both gender (youngest age 41 and eldest was 85 ). A total number of 50 patients in this study, $31(72 \%)$ were male patients and 19 (28\%) were female patients. This is similar to the study conducted by (Mark J Sarnak) in which a total of 14,410 patients $(6,267$ men and 8,143 women). [6] In our study, male were dominating than female, which is similar to the prevalence of coronary artery disease in India has been reported by Sinha, B.C. (1970).[7]

Majority of patient had hypertension $(62 \%)$ as a comorbidity condition followed by diabetes mellitus (40\%) and dyslipidaemia (18\%). The pattern of coronary artery disease in India has been reported. Hypertension and diabetes account for about 40 percent of all cases (Sinha, B.C. (1970).[7] is similar to the study conducted by (Mohan V) the overall prevalence of dyslipidaemia in the study population was significantly high (45.6\%) followed by hypertension $(22.4 \%)$ and diabetes mellitus (16\%). The maximum number of patients were in the age group 51 to 60 years were majority were males. Coronary artery disease appears a decade earlier compared with the age incidence in developed countries. The peak period is attained 
between 51-60 years (Sinha, B.C. (1970).[8] The study population was divided into four groups according to age. Subjects aged $41-50$ years $(n=10), 51-60$ years $(n=18), 61-70$ years $(n=10),>70(n=12)$ is similar to study conducted (T Sekhir) subjects aged 20-30 years $(n=1885), 30-40$ years $(n=2724), 40-50$ years $(n=3604)$, and $50-60$ years $(n=4395)$ were categorised as group I, group II, group III, group IV, respectively.[9]

In the present study, we observed anaemia in $80 \%$ with varying severity considering more patients with anaemia between 11-13 representing mild anaemia with supporting smear study dominated by microcytic hypochromic suggesting nutrition as the major cause for anaemia. The mean haemoglobin level in our study is $11.70 \mathrm{~g} / \mathrm{dL}$. The incidence of anaemia was $80 \%$ with varying severity $7-9(2 \%), 9-11(32 \%)$, $11-13(46 \%),>13(20 \%)$, and smear showed microcytic hypochromic dominated with $52 \%$ is similar to the study conducted by (G. Michael Felker) four thousand nine hundred and fifty one patients for this study. Anaemia was present in 1946 (39\%) and absent in 3005 (61\%). The mean Hb in this study $12.8 \mathrm{~g} / \mathrm{dL}$ [10] is similar to another study conducted by (Nicholas J. Kassebaum) in accordance with recently published WHO guidelines, optimizing nutrition, including targeted daily iron supplementation should be considered a high-prevalence groups.[11]

Upper gastroendoscopy was done in 8 patients in whom it was normal. Rest of the patient had stool occult blood negative and they were not willing for upper gastrointestinal endoscopy. Out of 50 patient with CAD, 18 patients were on antiplatelet already, out of which fourteen were on single antiplatelet (Clopidogrel), and 4 were on double antiplatelet (Aspirin+clopidogrel), out of them, no patient were evidence of GI bleeding. Our study has clearly shown that among the middle class Indian population, there is a high prevalence of obesity, hypertension, dyslipidaemia, and diabetes, which are all modifiable coronary artery disease risk factors. Coronary artery disease has a multifactorial aetiology with many of the risk factors being influenced by lifestyle. Rapid changes in dietary habits coupled with decreased physical activity in India as consequence of urbanization may partly explain the increase in coronary artery disease. India is experiencing an epidemiological transition with high rates of urbanisation.[12-14]

This has led to economic improvement. The consequences of which are increased fast food consumption and tobacco usage and decreased physical activity. With the introduction of an era of refined food, sugar, and hydrogenated oils, the traditional high complex carbohydrates, high-fibre and low-fat diet has been replaced by a diet rich in fats and simple sugars low in dietary.[15] One of the effects of this transition is a shift in the disease spectrum from communicable to noncommunicable diseases particularly coronary artery disease and diabetes.[16-18] More importantly, coronary artery disease is affecting young Indians who comprise the productive workforce. The incidence of coronary artery disease in young Indians is $12-16 \%$, which is higher than in other ethnic groups worldwide. Lack of awareness of the preventable risk factors and ignorance of the disease are also important factors responsible for the increasing rate of coronary artery disease among Indians. ${ }^{[19-23]}$

\section{CONCLUSION}

Incidence of anaemia found in rural population with reference to significances of role as risk factor yet to be studied with detailed study. The present study demonstrates a high prevalence of coronary artery disease in the rural population at the middle age. It is important to modify the risk factors in rural population for our country and to modify the risk factors prevention protocol.

\section{LIMITATIONS}

- The study population is n number.

- Not evaluated the cause of anaemic with detailed investigations.

\author{
ABBREVIATIONS \\ CAD-Coronary artery disease. \\ WHO-World health organization. \\ Hb-Haemoglobin. \\ PCV-Packed cell volume. \\ MCV-Mean corpuscular volume. \\ MCH-Mean cell haemoglobin. \\ MCHC-Mean cell haemoglobin concentration. \\ RBC-Red blood cell. \\ ECG-Electrocardiogram. \\ TC-Total count. \\ PLT-Platelet. \\ SD-Standard deviation.
}

\section{REFERENCES}

1. http:/www.healthepic.com/hotdisease/anaemia.htm.

2. WHO, Global anaemia prevalence and number of individuals affected, accessed 3 August 2015.

3. Misra A, Nigam P, Hills AP, et al. Consensus physical activity guidelines for Asian Indians. Diabetes Technol Ther 2012;14(1):83-98.

4. Indrayan A. Forecasting vascular disease cases and associated mortality in India. Reports of the national commission on macroeconomics and health. Ministry of Health And Family Welfare, Government of India, New Delhi 2005.

5. Reddy KS, Yusuf S. Emerging epidemic of cardiovascular disease in developing countries. Circulation 1998;97(6):596-601.

6. Sarnak MJ, Tighiouart H,Levey AS, et al. Anaemia as a risk factor for cardiovascular disease in: the atherosclerosis risk in communities (ARIC) study. J American college of cardiology 2002;40(1):27-33.

7. Park K. Park's textbook of preventive and social medicine. $19^{\text {th }}$ edn. Jabalpur, India: Bhanotpublishers 2007:305-8.

8. Sekhir T, Kanwar RS, Wilfred R, et al. Prevalence of risk factors for coronary artery disease in an urban Indian population. BMJ Open 2014;4:e00534.doi:10.1136/ bmjopen-2014-005346.

9. Felker GM, Stough WG, Shaw LK, et al. Anaemia and coronary artery disease severity in patients with heart failure. European journal of heart failure 2006;8(1):54-7.

10. World health organization. Essential nutrition actions: improving maternal, newborn, infant, and young child health and nutrition. Geneva, Switzerland: World health organization 2013. 
11. Pais P, Pogue J, Gerstein $\mathrm{H}$, et al. Risk factors for acute myocardial infarction in Indians: a case-control study. Lancet 1996;348(9024):358-63.

12. Ramanakumar AV. Reviewing disease burden among rural Indian women. Online J Health Allied Sci 2004;2:1.

13. Yusuf S, Hawken S, OunpuuS, et al. Effect of potentially modifiable risk factors associated with myocardial infarction in 52 countries (the inter heart study): casecontrol study. Lancet 2004;364(9438):937-52.

14. Drewnowski A, Popkin BM. The nutrition transition: new trends in the global diet. Nutr Rev 1997;55(2):31-43.

15. Sharma M, Ganguly NK. Premature coronary artery disease in Indians and its associated risk factors. Vasc Health Risk Manag 2005;1(3):217-25.

16. Mokdad AH, Ford ES, Bowman BA, et al. Prevalence of obesity, diabetes, and obesity-related health risk factors, 2001. JAMA 2003;289(1):76-9.

17. Mohan V, Deepa R, Rani SS, et al. Prevalence of coronary artery disease and its relationship to lipids in a selected population in South India: the Chennai urban population study (CUPS). J Am Coll Cardiol 2001;38(3):682-7.

18. Deepa R, Shanthirsni CS, Pradeepa R, et al. Is the rule of halves in hypertension still valid? Evidence from the Chennai urban population study. J Assoc Physicians India 2003;51:153-57.
19. Zacharian MG, Thankappan KR, Alex SC, et al. revalence, correlated, awareness, treatment and control of hypertension in a middle-aged urban population in Kerala. Indian Heart J 2003;55(3):245-51.

20. Gupta AK, Ahluwalia SK, Negi PC, et al. Awareness of hypertension among a north Indian population. J Indian Med Assoc 1998;96(10):298-9.

21. Chandha SL, Radhakrishnan S, Ramachandran K, et al. Prevalence, awareness, and treatment status of hypertension in urban population of Delhi. Indian J Med Res 1990;92:233-40.

22. Qiao $\mathrm{Q}, \mathrm{Hu} \mathrm{G}$, Tuomilehto J, et al. Age and sex-specific prevalence of diabetes and impaired-glucose regulation in 11 Asian cohorts. Diabetes Care 2003;26(6):1770-80.

23. Mohan V, Shanthirani CS, Deepa R. Glucose intolerance (diabetes and IGT) in a selected south Indian population with special reference to family history, obesity, and lifestyles factors-the Chennai Urban Population Study (CUPS14). J Assoc Physicians India 2003;51:771-7. 